Pacific Journal of Mathematics

BASIC SEQUENCES AND THE PALEY-WIENER CRITERION 


\title{
BASIC SEQUENCES AND THE PALEY-WIENER CRITERION
}

\author{
JAMES R. RETHERFORD
}

1. Introduction. Throughout the paper $X$ will denote a complete metric linear space (i.e., a complete topological linear space with topology derived from a metric $d$ with the property that $d(x, y)=d(x-y, 0)$, for all $x, y \in X$ ) or some specialization thereof over the real or complex field; $\|x\|$ will denote $d(x, 0)$; and if $\left\{x_{n}\right\}$ is a sequence in $X,\left[x_{n}\right]$ will denote the closed linear span of the elements $\left\{x_{n}\right\}_{n \in \omega}$.

A sequence $\left\{x_{n}\right\}$ is said to be a basic sequence of vectors if $\left\{x_{n}\right\}$ is a basis of vectors of the space $\left[x_{n}\right]$, i.e., for each $x \in\left[x_{n}\right]$ there corresponds a unique sequence of scalars $\left\{a_{i}\right\}$ such that

$$
x=\sum_{i=1}^{\infty} a_{i} x_{i}
$$

the convergence being in the topology of $X$. We say that the basis is unconditional if the convergence in (1.1) is unconditional. It is well known that if $\left\{x_{n}\right\}$ is a basic sequence of vectors, then every $x \in\left[x_{n}\right]$ can be represented in the form $x=\sum_{i=1}^{\infty} f_{i}(x) x_{i}$ where $\left\{f_{i}\right\}$ is the sequence of continuous coefficient functionals biorthogonal to $\left\{x_{i}\right\}$ (Arsove [1, p. 368], Dunford and Schwartz [4, p. 71]).

Similarly, we say that a sequence $\left\{M_{i}\right\}$ of nontrivial subspaces of a complete metric linear space $X$ is a basis of subspaces of $X$, if for each $x \in X$, there corresponds a unique sequence $\left\{x_{i}\right\}, x_{i} \in M_{i}$ for each $i$, such that

$$
x=\sum_{i=1}^{\infty} x_{i} .
$$

This concept has been studied by Fage [5], Markus [9], and others in separable Hilbert space and by Grimblyum [6] and McArthur [10] in complete metric linear spaces. We say that the basis of subspaces is unconditional if the convergence in (1.2) is unconditional.

If $\left\{M_{i}\right\}$ is a basis of subspaces for $X$, for each $i \in \omega$ define $E_{i}$ from $X$ into $X$ by $E_{i}(x)=x_{i}$ where $\sum_{i=1}^{\infty} x_{i}$ is the unique representation of $x \in X . E_{i}$ is a projection (linear and idempotent); $E_{i} E_{j}=0$ if $i \neq j$; the range of $E_{i}$ is $M_{i}$; for each $x \in X, x=\sum_{i=1}^{\infty} E_{i}(x)$ and if $E_{i}(x)=0$ for each $i$, then $x=0 . \quad\left\{M_{i}\right\}$ will be called a Schauder basis of subspaces if each $E_{i}$ is continuous.

September 24, 1962. This research was supported by the Air Force Office of Scientific Research. 
A sequence $\left\{M_{i}\right\}$ of non-trivial subspaces of $X$ is a (unconditional) basic sequence of subspaces if $\left\{M_{i}\right\}$ is a (unconditional) basis of subspaces of $\left[M_{i}\right]$, the closed linear span of $\bigcup_{i \in \omega} M_{i}$. If $\left\{M_{i}\right\}$ is a basic sequence of subspaces and $x \in\left[M_{i}\right]$ then $x=\sum_{i=1}^{\infty} E_{i}(x)$, where $E_{i}$ is now defined on $\left[M_{i}\right]$.

The classical Paley-Wiener theorem can be formulated in $X$ as follows.

1.3. TheOREM. Let $\left\{x_{n}\right\}$ and $\left\{y_{n}\right\}$ be sequences in $X$ and let $\lambda$ be a real number $(0<\lambda<1)$ such that

$$
\left\|\sum_{n=1}^{m} a_{n}\left(x_{n}-y_{n}\right)\right\| \leqq \lambda\left\|\sum_{n=1}^{m} a_{n} x_{n}\right\|
$$

holds for arbitrary scalars $a_{1}, \cdots, a_{m}$. Then (1) if $\left\{x_{n}\right\}$ is a basis so is $\left\{y_{n}\right\}$; (2) if $\left\{x_{n}\right\}$ is fundamental (i.e., $\left[x_{n}\right]=X$ ) so is $\left\{y_{n}\right\}$.

Recently Arsove [1] showed that Theorem 1.3 is valid in a complete metric linear space. It is the purpose of this paper to show that this result and results similar to those of Pollard [13], Hilding [7], and Nagy [11] (all of which generalize condition 1.3a) are valid for basic sequences of subspaces in $X$. As a corollary to Theorem 4.3 we obtain a new version of the Paley-Wiener theorem.

The author wishes to express his gratitude to Professor C. W. McArthur for his help and encouragement in the preparation of this paper.

2. Basic sequences of subspaces. Special cases of the following lemma have been used by Hilding [7, p. 93], Nagy [11, p. 76], and others to prove theorems similar to Theorems 2.3 and 2.4 .

2.1. Lemma. Let $\left\{M_{i}\right\}$ and $\left\{N_{i}\right\}$ be sequences of nontrivial subspaces of the complete metric linear space $X$. Suppose that for each $i \in \omega$ there exists a one-to-one linear transformation $T_{i}$ of $M_{i}$ onto $N_{i}$ and suppose further that there are positive numbers $m, M$ such that

$$
m\left\|\sum_{i=1}^{p} x_{i}\right\| \leqq\left\|\sum_{i=1}^{p} T_{i}\left(x_{i}\right)\right\| \leqq M\left\|\sum_{i=1}^{p} x_{i}\right\|
$$

holds for arbitrary $x_{i} \in M_{i}, i=1, \cdots, p$. Then

(i) there is a linear homeomorphism $T$ of $\left[M_{i}\right]$ onto $\left[N_{i}\right]$ such that the restriction of $T$ to $M_{i}$ equals $T_{i}$ for each $i \in \omega$ and such that

$$
m\|x\| \leqq\|T(x)\| \leqq M\|x\|, \text { for all } x \in\left[M_{i}\right] \text {. }
$$


(ii) $\left\{M_{i}\right\}$ is a (unconditional) basic sequence of subspaces if and only if $\left\{N_{i}\right\}$ is a (unconditional) basic sequence of subspaces.

Proof. Let $X_{0}$ denote the space of finite linear combinations of $\bigcup_{i \in \omega} M_{i}$. These, of course, are reducible to the form $\sum_{i=1}^{n} x_{i}, x_{i} \in M_{i}$. If $x_{i}, x_{i}^{\prime} \in M_{i}, i=1, \cdots, p$ and $\sum_{i=1}^{p} x_{i}=\sum_{i=1}^{p} x_{i}^{\prime}$ then from 2.1a it follows that $\sum_{i=1}^{p} T_{i}\left(x_{i}\right)=\sum_{i=1}^{p} T_{i}\left(x_{i}^{\prime}\right)$. Thus we may define a linear transformation $S$ from $X_{0}$ into $\left[N_{i}\right]$ by $S\left(\sum_{i=1}^{p} x_{i}\right)=\sum_{i=1}^{p} T_{i}\left(x_{i}\right)$ and have $m\|x\| \leqq\|S(x)\| \leqq M\|x\|$, for all $x \in X_{0}$. It is clear that $S$ restricted to $M_{i}$ is equal to $T_{i}$ and that $S$ is continuous. Thus defined on a dense subset of $\left[M_{i}\right], S$ has a unique linear extension $T$ to $\left[M_{i}\right]$ satisfying $2.1 \mathrm{~b}$. From $2.1 \mathrm{~b}$ it follows that $T$ is one-to-one and $T^{-1}$ is continuous. We show $T$ is onto $\left[N_{i}\right]$.

Let $y \in\left[N_{i}\right]$. Then $y=\lim _{k} g_{k}$ where $g_{k}$ is of the form $g_{k}=\sum_{i=1}^{n(k)} y_{i}^{(k)}$, $y_{i}^{(k)} \in N_{i}, i=1, \cdots, n(k)$. For each such $y_{i}^{(k)}$ there is a unique $x_{i}^{(k)} \in M_{i}$ such that $T_{i}\left(x_{i}^{(k)}\right)=y_{i}^{(k)}$. Let $h_{k}=\sum_{i=1}^{n(k)} x_{i}^{(k)}$. Then from 2.1b, $\left\|h_{p}-h_{q}\right\| \leqq(1 / m)\left\|g_{p}-g_{q}\right\|$, so $\left\{h_{k}\right\}$ is Cauchy and there is an $x_{0} \in\left[M_{i}\right]$ such that $\left\{h_{k}\right\} \rightarrow x_{0}$. Clearly, $T\left(x_{0}\right)=y$.

To verify (ii) suppose $\left\{M_{i}\right\}$ is basic, i.e., a basic sequence of subspaces. Let $y \in\left[N_{i}\right]$. Then $y=T(x)$ for some $x \in\left[M_{i}\right] . x$ has a. unique expansion $x=\sum_{i=1}^{\infty} x_{i}, x_{i} \in M_{i}$ and $y=\sum_{i=1}^{\infty} T\left(x_{i}\right), T\left(x_{i}\right) \in N_{i}$. Now if $y=\sum_{i=1}^{\infty} y_{i}, y_{i} \in N_{i}$, then $y_{i}=T\left(x_{i}^{\prime}\right)$ for some unique $x_{i}^{\prime} \in M_{i}$. Hence $0=T\left(\sum_{i=1}^{\infty} x_{i}-x_{i}^{\prime}\right)$ which implies $x_{i}=x_{i}^{\prime}$. Since the expansion for $y$ is unique, it follows that $\left\{N_{i}\right\}$ is basic. The converse follows. from (i) in the same way. If in the preceding argument $\left\{M_{i}\right\}$ had been assumed an unconditional basis of subspaces for $\left[M_{i}\right]$ then the series $\sum_{i=1}^{\infty} x_{i}$ would have been unconditionally convergent to $x$ and since $T$ is a linear homeomorphism it follows that $\sum_{i=1}^{\infty} T\left(x_{i}\right)$ would be unconditionally convergent.

2.2. Definition. Two sequences $\left\{x_{i}\right\}$ and $\left\{y_{i}\right\}$ (in the given order), in $X$ are said to have the property:

(P-W) (for Paley-Wiener) if there is a real number $\lambda(0<\lambda<1)$ such that $\left\|\sum_{i=1}^{n} a_{i}\left(x_{i}-y_{i}\right)\right\| \leqq \lambda\left\|\sum_{i=1}^{n} a_{i} x_{i}\right\|$ holds for arbitrary scalars. $a_{1}, a_{2}, \cdots, a_{n}$

(P-H) (for Pollard-Hilding) if for each positive real number $k$, there are real numbers $\lambda_{1}, \lambda_{2}\left(0 \leqq \lambda_{i}<\min \left[1 ; 2^{1-1 / k}\right], i=1,2\right)$ such that.

$$
\left\|\sum_{i=1}^{n} a_{i}\left(x_{i}-y_{i}\right)\right\| \leqq\left[\lambda_{1}\left\|\sum_{i=1}^{n} a_{i} x_{i}\right\|^{k}+\lambda_{2}\left\|\sum_{i=1}^{n} a_{i} y_{i}\right\|^{k}\right]^{1 / k}
$$

holds for arbitrary scalars $a_{1}, \cdots, a_{n}$;

(N) (for Nagy) if there are real numbers $\lambda^{\prime}, \mu, \nu\left(0 \leqq \lambda^{\prime}<1,0 \leqq\right.$ $\left.\nu<1,0 \leqq \mu, \mu^{2} \leqq\left[1-\lambda^{\prime}\right][1-\nu]\right)$ such that 


$$
\left\|\sum_{i=1}^{n} a_{i}\left(x_{i}-y_{i}\right)\right\|^{2} \leqq \lambda^{\prime}\left\|\sum_{i=1}^{n} a_{i} x_{i}\right\|^{2}+\mu\left\|\sum_{i=1}^{n} a_{i} x_{i}\right\| \cdot\left\|\sum_{i=1}^{n} a_{i} y_{i}\right\|+\nu\left\|\sum_{i=1}^{n} a_{i} y_{i}\right\|^{2}
$$

holds for arbitrary scalars $a_{1}, \cdots, a_{n}$.

If $k=1$ and $\lambda_{1}=\lambda_{2}$ property $\mathrm{P}-\mathrm{H}$ reduces to

$$
\left\|\sum_{i=1}^{n} a_{i}\left(x_{i}-y_{i}\right)\right\| \leqq \lambda\left[\left\|\sum_{i=1}^{n} a_{i} y_{i}\right\|+\left\|\sum_{i=1}^{n} a_{i} x_{i}\right\|\right]
$$

where $\lambda=\lambda_{1}=\lambda_{2}$.

2.3. LemMA. If $\left\{x_{n}\right\}$ and $\left\{y_{n}\right\}$ are sequences in $X$ with property $\mathrm{P}-\mathrm{W}, \mathrm{P}-\mathrm{H}$ or $\mathrm{N}$ then $2.2 \mathrm{a}$ holds, with $\lambda(0<\lambda<1)$ an appropriately chosen constant.

Proof. That property $\mathrm{P}-\mathrm{W}$ implies $2.2 \mathrm{a}$ is obvious. If $\left\{x_{n}\right\},\left\{y_{n}\right\}$ have property $\mathrm{P}-\mathrm{H}$, let $\lambda=\left[\max \left(\lambda_{1}, \lambda_{2}\right)\right]^{1 / k}$; if $\left\{x_{n}\right\},\left\{y_{n}\right\}$ have property $N$ let $\lambda=\left[\max \left(\lambda^{\prime}, \mu, \nu\right)\right]^{1 / 2}$.

2.4. Theorem. Suppose $\left\{M_{i}\right\}$ and $\left\{N_{i}\right\}$ are sequences of nontrivial subspaces of $X$ and suppose that for each $i \in \omega, T_{i}$ is a one-to-one linear transformation of $M_{i}$ onto $N_{i}$. Suppose further that there is a $\lambda(0<\lambda<1)$ such that

$$
\left\|\sum_{i=1}^{n}\left(x_{i}-T_{i}\left(x_{i}\right)\right)\right\| \leqq \lambda\left(\left\|\sum_{i=1}^{n} x_{i}\right\|+\left\|\sum_{i=1}^{n} T_{i}\left(x_{i}\right)\right\|\right)
$$

holds for arbitrary $x_{i} \in M_{i}, i=1, \cdots, n$. Then

(i) there is a linear homeomorphism $T$ of $\left[M_{i}\right]$ onto $\left[N_{i}\right]$ such that $T$ restricted to $M_{i}$ equals $T_{i}$ for each $i$ and such that

$$
[(1-\lambda) /(1+\lambda)]\|x\| \leqq\|T(x)\| \leqq[(1+\lambda) /(1-\lambda)]\|x\|
$$

for each $x \in\left[M_{i}\right]$

(ii) $\left\{M_{i}\right\}$ is a (unconditional) basic sequence of subspaces if and only if $\left\{N_{i}\right\}$ is a (unconditional) basic sequence of subspaces.

Proof.

$$
\begin{aligned}
\left\|\sum_{i=1}^{n} T_{i}\left(x_{i}\right)\right\| \leqq\left\|\sum_{i=1}^{n}\left(T_{i}\left(x_{i}\right)-x_{i}\right)\right\| & +\left\|\sum_{i=1}^{n} x_{i}\right\| \\
& \leqq(1+\lambda)\left\|\sum_{i=1}^{n} x_{i}\right\|+\lambda\left\|\sum_{i=1}^{n} T_{i}\left(x_{i}\right)\right\|,
\end{aligned}
$$

i.e.,

$$
\left\|\sum_{i=1}^{n} T_{i}\left(x_{i}\right)\right\| \leqq[(1+\lambda) /(1-\lambda)]\left\|\sum_{i=1}^{n} x_{i}\right\|
$$


Similarly,

$$
\left\|\sum_{i=1}^{n} x_{i}\right\| \leqq[(1+\lambda) /(1-\lambda)]\left\|\sum_{i=1}^{n} T_{i}\left(x_{i}\right)\right\|
$$

Thus

$$
[(1-\lambda) /(1+\lambda)]\left\|\sum_{i=1}^{n} x_{i}\right\| \leqq\left\|\sum_{i=1}^{n} T_{i}\left(x_{i}\right)\right\| \leqq[(1+\lambda) /(1-\lambda)]\left\|\sum_{i=1}^{n} x_{i}\right\| .
$$

The conclusions follow from Lemma 2.1.

2.5. Corollary. Suppose $\left\{M_{i}\right\}$ and $\left\{N_{i}\right\}$ are sequences of nontrivial subspaces of $X$ and suppose that for each $i \in \omega, T_{i}$ is a oneto-one linear transformation of $M_{i}$ onto $N_{i}$. Suppose further that $\left\{x_{i}\right\}$ and $\left\{T_{i}\left(x_{i}\right)\right\}$ have property $\mathrm{P}-\mathrm{W}, \mathrm{P}-\mathrm{H}$ or $N$, for arbitrary $x_{i} \in M_{i}$ (observe that since $x_{i} \in M_{i}$ is arbitrary, $x_{i}$ and $T_{i}\left(x_{i}\right)$ include the scalar $a_{i}$ for each i) then the conclusions of Theorem 2.4 hold. In particular, if Property $\mathrm{P}-\mathrm{W}$ holds and $\left\{M_{i}\right\}$ is a basis of subspaces for $X$, so is $\left\{N_{i}\right\}$.

Proof. The first part of the corollary follows from Lemma 2.3. Arsove [1, p. 367] has shown how to prove the other assertion of the corollary. We repeat the proof for completeness.

Since Property P-W holds there exists a linear operator $T$ from $X$ into $X$ satisfying $\|x-T(x)\| \leqq \lambda\|x\|, x \in X$ and such that $T$ restricted to $M_{i}$ equals $T_{i}$. Let $A=T-I$, where $I$ is the identity operator. $A$ is continuous at each $x \in X$ and furthermore $\left\|A^{n}(x)\right\| \leqq$ $\lambda^{n}\|x\|$ for each $x \in X$ and positive integer $n$. Thus a linear operator $U$ of $X$ onto $X$ may be defined by $U(x)=\sum_{n=0}^{\infty}\left(-A^{n}(x)\right), x \in X$. It follows that $\|U(x)\| \leqq(1-\lambda)^{-1}\|x\|$, so $U$ is continuous. Given $y \in X$, let $x=U(y)$. Then $y=(I+A) x=T(x)$ so $T$ is onto $X$. Thus $\left\{N_{i}\right\}$ is a basis of subspaces for $X$.

3. Basic sequences of vectors. If $X$ has a basis of vectors $\left\{x_{n}\right\}$, then $\left\{x_{n}\right\}$ induces in a natural way a basis of subspaces $\left\{M_{i}\right\}$ for $X$. We have only to define $M_{i}$ to be the span of the single element $x_{i}$ (denoted by $s p\left(x_{i}\right)$ ). From the remarks in the introduction we have $x=\sum_{i=1}^{\infty} f_{i}(x) x_{i}$ for each $x \in X$, so $E_{i}(x)=f_{i}(x) x_{i}$. Since $h(a)=a x_{i}$ is a linear homeomorphism of the scalar field into $X$ and $f_{i}(x)$ is a continuous linear functional it follows that $E_{i}$ is continuous for each $i \in \omega$ and so $\left\{M_{i}\right\}$ is a Schauder basis of subspaces for $X$. Thus, for Schauder bases of vectors, we obtain the following theorems as corollaries to the theorems of $\S 2$. 
3.1. THEOREM. Suppose $\left\{x_{i}\right\}$ and $\left\{y_{i}\right\}$ are nontrivial (i.e., $x_{i} \neq 0$, $y_{i} \neq 0$, for each $\left.i \in \omega\right)$ sequences in $X$ and suppose there is a $\lambda(0<\lambda<1)$ such that

$$
\left\|\sum_{i=1}^{n} a_{i}\left(x_{i}-y_{i}\right)\right\| \leqq \lambda\left(\left\|\sum_{i=1}^{n} a_{i} x_{i}\right\|+\left\|\sum_{i=1}^{n} a_{i} y_{i}\right\|\right)
$$

holds for arbitrary scalars $a_{1}, \cdots, a_{n}$. Then,

(i) there exists a linear homeomorphism $T$ of $\left[x_{i}\right]$ onto $\left[y_{i}\right]$ such that $T\left(x_{i}\right)=y_{i}$ for each $i \in \omega$, and

(ii) $\left\{x_{i}\right\}$ is a (unconditional) basic sequence of vectors if and only if $\left\{y_{i}\right\}$ is a (unconditional) basic sequence of vectors.

Proof. Let $M_{i}=s p\left(x_{i}\right)$ and $N_{i}=s p\left(y_{i}\right)$. Define a linear operator $T_{i}$ from $M_{i}$ onto $N_{i}$ by $T_{i}\left(a x_{i}\right)=a y_{i}$ where $a$ is an arbitrary scalar. Clearly, $T_{i}$ is one-to-one and continuous. $3.1 \mathrm{a}$ can be rewritten

$$
\left\|\sum_{i=1}^{n}\left(x_{i}^{\prime}-T_{i}\left(x_{i}^{\prime}\right)\right)\right\| \leqq \lambda\left(\left\|\sum_{i=1}^{n} x_{i}^{\prime}\right\|+\left\|\sum_{i=1}^{n} T_{i}\left(x_{i}^{\prime}\right)\right\|\right)
$$

for arbitrary $x_{i}^{\prime} \in M_{i}, i=1, \cdots, n$. The conclusions follow from Theorem 2.4.

Thus in particular, if $\left\{x_{n}\right\}$ and $\left\{y_{n}\right\}$ are nontrivial sequences in $X$ with property $\mathrm{P}-\mathrm{W}, \mathrm{P}-\mathrm{H}$ or $\mathrm{N}$, the conclusions of 3.1 are valid.

We have remarked that if $\left\{x_{n}\right\}$ and $\left\{y_{n}\right\}$ have property $\mathrm{P}-\mathrm{W}$ and $\left\{x_{n}\right\}$ is a basis of vectors for $X$, then $\left\{y_{n}\right\}$ is a basis of vectors for $X$. From 3.1 it follows that if $\left\{x_{n}\right\}$ is an unconditional basis of vectors for $X$, then $\left\{y_{n}\right\}$ is an unconditional basis of vectors for $X$.

4. Basic sequences in Banach spaces. From Grinblyum [6] the following can be derived (a proof is given in [10]).

4.1. Lemma. Let $\left\{M_{i}\right\}$ be sequence a of nontrivial closed subspaces in a Banach space $X .\left\{M_{i}\right\}$ is a Schauder basis of subspace for $\left[M_{i}\right]$ if and only if there is a $K \geqq 1$ such that for arbitrary $p, q \in \omega$, $p \leqq q$ we have $\left\|\sum_{i=1}^{p} x_{i}\right\| \leqq K\left\|\sum_{i=1}^{q} x_{i}\right\|$, for arbitrary $x_{i} \in M_{i}, i=$ $1, \cdots, q$.

4.2. Lemma. Let $\left\{M_{i}\right\}$ be a sequence of nontrivial closed subspaces of a Banach space $X .\left\{M_{i}\right\}$ is an unconditional Schauder basis of subspaces of $\left[M_{i}\right]$ if and only if there is a $K \geqq 1$ such that for arbitrary finite sets of positive integers $F, F^{\prime}$ with $F \subset F^{\prime}$ we have $\left\|\sum_{i \in F} x_{i}\right\| \leqq K\left\|\sum_{i \in F^{\prime}} x_{i}\right\|$, for arbitrary $x_{i} \in M_{i}$.

4.3. THeorem. Suppose $\left\{M_{i}\right\}$ and $\left\{N_{i}\right\}$ are sequences of closed nontrivial subspaces of a Banach space $X$. 
(1) If there is a $\lambda(0<\lambda<1)$ such that for an arbitrary finite set of integers $F^{\prime}$ and arbitrary $y_{i} \in N_{i}, i \in F^{\prime}$, there exists $x_{i} \in M_{i}$, $i \in F^{\prime}$ such that

$$
\left\|\sum_{i \in F}\left(y_{i}-x_{i}\right)\right\| \leqq \lambda\left[\left\|\sum_{i \in F} x_{i}\right\|+\left\|\sum_{i \in F} y_{i}\right\|\right]
$$

holds for arbitrary $F \subset F^{\prime}$ then $\left\{N_{i}\right\}$ is an unconditional (Schauder) basic sequence of subspaces if $\left\{M_{i}\right\}$ is an unconditional (Schauder) basic sequence of subspaces;

(2) if there is a $\lambda(0<\lambda<1)$ such that for arbitrary $q \in \omega$ and arbitrary $y_{1}, \cdots, y_{q}, y_{i} \in N_{i}, i=1, \cdots, q$ there exist $x_{1}, \cdots, x_{q}, x_{i} \in M_{i}$, $i=1, \cdots, q$ such that

$$
\left\|\sum_{i=1}^{p}\left(y_{i}-x_{i}\right)\right\| \leqq \lambda\left[\left\|\sum_{i=1}^{p} x_{i}\right\|+\left\|\sum_{i=1}^{p} y_{i}\right\|\right]
$$

holds for all $p \leqq q$ then $\left\{N_{i}\right\}$ is a (Schauder) basic sequence of subspaces if $\left\{M_{i}\right\}$ is a (Schauder) basic sequence of subspaces.

Proof. We prove (2). The proof of (1) is analogous using Lemma 4.2 instead of 4.1 .

Suppose $\left\{M_{i}\right\}$ be a basis of subspaces for $\left[M_{i}\right]$. By Lemma 4.1 there is a $K \geqq 1$ such that

$$
\left\|\sum_{i=1}^{p} x_{i}\right\| \leqq K\left\|\sum_{i=1}^{q} x_{i}\right\|, x_{i} \in M_{i}, p \leqq q
$$

We have

$$
\left\|\sum_{i=1}^{p} y_{i}\right\| \leqq\left\|\sum_{i=1}^{p}\left(y_{i}-x_{i}\right)\right\|+\left\|\sum_{i=1}^{p} x_{i}\right\|
$$

and from $(4.4 b)$ it follows that

$$
\left\|\sum_{i=1}^{p} y_{i}\right\| \leqq \frac{1+\lambda}{1-\lambda}\left\|\sum_{i=1}^{p} x_{i}\right\|
$$

Also

$$
\left\|\sum_{i=1}^{q} x_{i}\right\| \leqq \frac{1+\lambda}{1-\lambda}\left\|\sum_{j=1}^{q} y_{i}\right\|
$$

Thus we have

$$
\left\|\sum_{i=1}^{p} y_{i}\right\| \leqq\left[\frac{1+\lambda}{1-\lambda}\right]^{2} K\left\|\sum_{i=1}^{q} y_{i}\right\|
$$

Thus by Lemma 4.1, $\left\{N_{i}\right\}$ is a basis of subspaces for $\left[N_{i}\right]$. 
4.4. Corollary. Let $\left\{x_{i}\right\}$ and $\left\{y_{i}\right\}$ be non-trivial sequences in a Banach space $X$.

(1) If there is a $\lambda(0<\lambda<1)$ such that for an arbitrary finite set of indices $F^{\prime}$ and arbitrary scalars $\left\{a_{i}\right\}, i \in F^{\prime \prime}$, there exist scalars $\left\{b_{i}\right\}, i \in F^{\prime}$, such that

$$
\left\|\sum_{i \in F}\left(a_{i} y_{i}-b_{i} x_{i}\right)\right\| \leqq \lambda\left[\left\|\sum_{i \in F} a_{i} y_{i}\right\|+\left\|\sum_{i \in F} b_{i} x_{i}\right\|\right]
$$

holds for arbitrary $F \subset F^{\prime}$ then $\left\{y_{i}\right\}$ is an unconditional (Schauder) basic sequence of vectors if $\left\{x_{i}\right\}$ is an unconditional (Schauder) basic sequence of vectors;

(2) if there is a $\lambda(0<\lambda<1)$ such that for arbitrary $q \in \omega$ and arbitrary scalars $a_{1}, \cdots, a_{q}$ there are scalars $b_{1}, \cdots, b_{q}$ such that

$$
\left\|\sum_{i=1}^{p}\left(a_{i} y_{i}-b_{i} x_{i}\right)\right\| \leqq \lambda\left[\left\|\sum_{i=1}^{p} b_{i} x_{i}\right\|+\left\|\sum_{i=1}^{p} a_{i} y_{i}\right\|\right]
$$

holds for all $p \leqq q$ then $\left\{y_{i}\right\}$ is a (Schauder) basic sequence of vectors if $\left\{x_{i}\right\}$ is a(Schauder) basic sequence of vectors.

Proof. Let $M_{i}=s p\left(x_{i}\right), N_{i}=s p\left(y_{i}\right)$ and apply the preceeding theorem.

4.4 is a new form of the Paley-Wiener theorem for we no longer require the coefficients of $x_{i}$ and $y_{i}$ to be the same. We could now define properties similar to properties $\mathrm{P}-\mathrm{W}, \mathrm{P}-\mathrm{H}$ and $N$ by merely asserting the existence of a scalar $b_{i}$ to replace the coefficient of $x_{i}$ in each of the properties defined in 2.2. It is easy to see that these new forms of properties $\mathrm{P}-\mathrm{W}, \mathrm{P}-\mathrm{H}$ and $N$ imply the hypotheses of corollary 4.5 .

It is unknown $n_{\text {T. }}$ to the author whether $\left[x_{n}\right]$ is linearly homeomorphic. to $\left[y_{n}\right]$ or not.

\section{REFERENCES}

1. M. G. Arsove, The Paley-Wiener theorem in metric linear spaces, Pacific J. Math., 10 (1930), 365-379.

2. C. Bessaga and A. Pelczynski, On bases and unconditional conditional convergence of series in Banach spaces, Studia Math., 17 (1958), 151-164.

3. M. M. Day, Normed linear spaces, Springer-Verlag, Berlin, 1958.

4. N. Dunford and J. T. Schwartz, Linear Operators, Part I, Interscience Publishers, New York, 1958.

5. M. K. Fage, The rectification of bases in Hilbert space, Dok1. Akad. Nauk., SSSR (N.S.) 75 (1950), 1053-1056 (In Russian).

6. M. M. Grinblyum, On the representation of a space of type $B$ in the form of a. direct sum of subspaces, Dokl. Akad. Nauk. SSSR (N.S.) 70 (749-752. 
7. S. H. Hilding, Note on completeness theorems of Paley-Wiener type, Ann. of Math., (2) 49 (1948), 953-955.

8. M. Krein, D. Milman and M. Rutman, On a property of a basis in a Banach space, Khark. Zap. Matem. Obsh. (4), 16 (1940), 182. (In Russian with English Resume).

9. A. S. Markus, A basis of root vectors of a dissipative operator, Soviet Math.-Doklady, Amer. Math. Soc. Trans. 1 (1960), 599-602.

10. C. W. McArthur. Infinite direct sums in complete metric linear spaces (to appear). 11. B. Sz. Nagy, Expansion theorems of Paley-Wiener type, Duke Math. J., 14 (1947), 975-978.

12. R. E. A. C. Paley and N. Wiener, Fourier transforms in the complex domain, New York, 1934.

13 H. Pollard, Completeness theorems of Paley-Wiener type, Ann. of Math. (2) 45 (1944), 738-739.

FLORIDA STATE UNIVERSITY 



\section{PACIFIC JOURNAL OF MATHEMATICS}

\section{EDITORS}

\author{
Robert Osserman \\ Stanford University \\ Stanford, California
M. G. Arsove
University of Washington
Seattle 5 , Washington

\author{
J. DugundJI \\ University of Southern California \\ Los Angeles 7, California
}

Lowell J. Paige

University of California

Los Angeles 24, California

\section{ASSOCIATE EDITORS}
E. F. BECKENBACH
B. H. NeumanN
F. WOLF
K. YOSIDA

\section{SUPPORTING INSTITUTIONS}

\author{
UNIVERSITY OF BRITISH COLUMBIA \\ CALIFORNIA INSTITUTE OF TECHNOLOGY \\ UNIVERSITY OF CALIFORNIA \\ MONTANA STATE UNIVERSITY \\ UNIVERSITY OF NEVADA \\ NEW MEXICO STATE UNIVERSITY \\ OREGON STATE UNIVERSITY \\ UNIVERSITY OF OREGON \\ OSAKA UNIVERSITY \\ UNIVERSITY OF SOUTHERN CALIFORNIA
}

\author{
STANFORD UNIVERSITY \\ UNIVERSITY OF TOKYO \\ UNIVERSITY OF UTAH \\ WASHINGTON STATE UNIVERSITY \\ UNIVERSITY OF WASHINGTON \\ * * * * \\ AMERICAN MATHEMATICAL SOCIETY \\ CALIFORNIA RESEARCH CORPORATION \\ SPACE TECHNOLOGY LABORATORIES \\ NAVAL ORDNANCE TEST STATION
}

Mathematical papers intended for publication in the Pacific Journal of Mathematics should by typewritten (double spaced), and on submission, must be accompanied by a separate author's résumé. Manuscripts may be sent to any one of the four editors. All other communications to the editors should be addressed to the managing editor, L. J. Paige at the University of California, Los Angeles 24, California.

50 reprints per author of each article are furnished free of charge; additional copies may be obtained at cost in multiples of 50 .

The Pacific Journal of Mathematics is published quarterly, in March, June, September, and December. Effective with Volume 13 the price per volume (4 numbers) is $\$ 18.00$; single issues, $\$ 5.00$. Special price for current issues to individual faculty members of supporting institutions and to individual members of the American Mathematical Society: $\$ 8.00$ per volume; single issues $\$ 2.50$. Back numbers are available.

Subscriptions, orders for back numbers, and changes of address should be sent to Pacific Journal of Mathematics, 103 Highland Boulevard, Berkeley 8, California.

Printed at Kokusai Bunken Insatsusha (International Academic Printing Co., Ltd.), No. 6, 2-chome, Fujimi-cho, Chiyoda-ku, Tokyo, Japan.

PUBLISHED BY PACIFIC JOURNAL OF MATHEMATICS, A NON-PROFIT CORPORATION

The Supporting Institutions listed above contribute to the cost of publication of this Journal, but they are not owners or publishers and have no responsibility for its content or policies. 


\section{Pacific Journal of Mathematics}

\section{Vol. 14, No. $3 \quad$ July, 1964}

Erik Balslev and Theodore William Gamelin, The essential spectrum of a class of ordinary differential operators . . . . . . . . . . . . . . . . . . . .

James Henry Bramble and Lawrence Edward Payne, Bounds for derivatives in

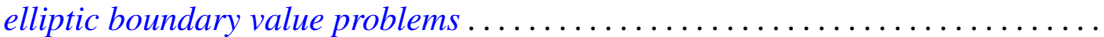

Hugh D. Brunk, Integral inequalities for functions with nondecreasing

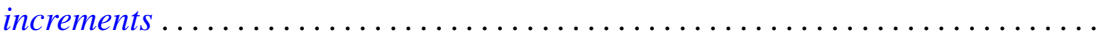

William Edward Christilles, A result concerning integral binary quadratic

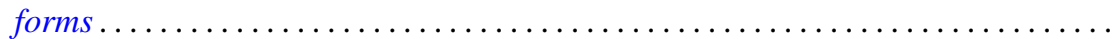

Peter Crawley and Bjarni Jónsson, Refinements for infinite direct decompositions of

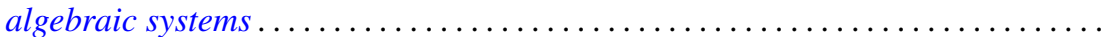

Don Deckard and Carl Mark Pearcy, On continuous matrix-valued functions on a Stonian space.

Raymond Frank Dickman, Leonard Rubin and P. M. Swingle, Another

characterization of the $n$-sphere and related results $\ldots \ldots \ldots \ldots \ldots \ldots$

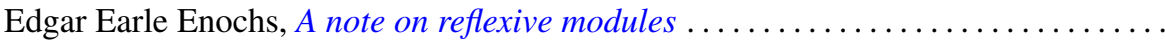

Vladimir Filippenko, On the reflection of harmonic functions and of solutions of the

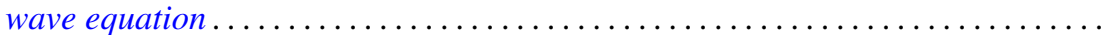

Derek Joseph Haggard Fuller, Mappings of bounded characteristic into arbitrary

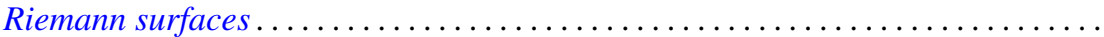
895

Curtis M. Fulton, Clifford vectors . . . . . . . . . . . . . . . . . . . . . . . . . . . . . . 917

Irving Leonard Glicksberg, Maximal algebras and a theorem of Radó . .

919

Kyong Taik Hahn, Minimum problems of Plateau type in the Bergman metric

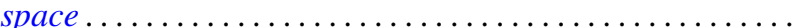

A. Hayes, A representation theory for a class of partially ordered rings...

J. M. C. Joshi, On a generalized Stieltjes trasform

J. M. C. Joshi, Inversion and representation theorems for a generalized Laplace transform ...

Eugene Kay McLachlan, Extremal elements of the convex cone $B_{n}$ of functions ...

Robert Alan Melter, Contributions to Boolean geometry of p-rings ...

James Ronald Retherford, Basic sequences and the Paley-Wiener criterion . . . . . . . 1019

Dallas W. Sasser, Quasi-positive operators. .

Oved Shisha, On the structure of infrapolynomials with prescribed coefficients ..

Oved Shisha and Gerald Thomas Cargo, On comparable means

Maurice Sion, A characterization of weak ${ }^{*}$ convergence ........

Morton Lincoln Slater and Robert James Thompson, A permanent inequality for

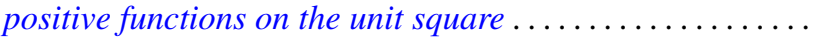

David A. Smith, On fixed points of automorphisms of classical Lie algebras ...

Sherman K. Stein, Homogeneous quasigroups ................

J. L. Walsh and Oved Shisha, On the location of the zeros of some infrapolynomials with prescribed coefficients .

Ronson Joseph Warne, Homomorphisms of $d$-simple inverse semigroups with identity . 